\title{
Análise e avaliação da deterioração do revestimento de mármore da cúpula da Catedral Metropolitana de Porto Alegre, RS
}

\author{
Ruy Paulo Philipp ${ }^{1}$ \& Verônica Di Benedetti ${ }^{2}$
}

\begin{abstract}
Resumo A Catedral Metropolitana de Porto Alegre - RS, projetada em estilo neo-renascentista pelo arquiteto romano João Batista Giovenalle, teve seu período construtivo compreendido entre 1921 e 1986. O corpo externo da igreja foi edificado em granito equigranular róseo proveniente da área urbana de Porto Alegre. Já a sua imponente cúpula apresenta como revestimento placas de mármore dolomítico silicoso proveniente do Estado do Espírito Santo. Originalmente, o revestimento especificado pelo autor do projeto para este elemento arquitetônico era o cobre, porém por motivos de ordem financeira o revestimento foi substituído pelo mármore. Contudo, não foram realizadas as adequações projetuais necessárias para o perfeito funcionamento do revestimento escolhido, resultando assim numa série de patologias que acabaram por comprometer não só a estética do revestimento bem como sua integridade física. Os problemas estruturais e materiais identificados na cúpula foram resultado da atuação dos processos intempéricos, resultando na deterioração e degradação da obra.
\end{abstract}

Palavras-chave: patrimônio cultural, rochas ornamentais, intemperismo, técnicas de conservação, educação.

\begin{abstract}
Analysis and evaluation of deterioration of the marble cover of the cupola of the Metropolitan Cathedral of Porto Alegre, RS. The Metropolitan Cathedral of Porto Alegre, in Rio Grande do Sul state, was designed by roman architect João Batista Giovenalle. This construction was developed in a long time between 1921 and 1986. The external building design has a match of granite and marble. In the body of the church was used rose equigranular granite extracted from a quarry located in Porto Alegre. Its imposing dome has covering of siliceous dolomitic marble drew out from quarry of Espírito Santo state. Originally the author of the project planned to recover this architectural element with copper, but this material was replaced by marble due to financial difficulties. However it wasn't planned the necessary suitableness structures to perfect operation of this new material and resulted in a series of pathologies that damaged its aesthetic satisfactory design and the own building. The structural and materials problems identified in external dome resulted of degradations mechanisms related to physical, chemical and biologic weathering.
\end{abstract}

Keywords: Cultural heritage, ornamental rocks, weathering, conservation techniques, education.

INTRODUÇÃO Desde os primórdios da história da humanidade o homem produz bens materiais e imateriais como um registro de sua evolução tecnológica e cultural. O patrimônio edificado faz parte deste legado e conta a história da evolução do homem através dos séculos. Dentre as categorias dos bens culturais de valor no patrimônio histórico, o representado pelas edificações é aquele que mais vidas envolvem numa relação direta e cognitiva.

O uso de rocha como material de construção em edificações, pavimentação e manufatura de objetos de adorno vinculados a rituais religiosos ou como adorno pessoal é reconhecido e descrito entre as primeiras grandes civilizações como na Mesopotâmia e Suméria, aproximadamente a 3000 AC. Nestas civilizações observa-se o uso de rochas na construção de templos, palácios e edificações urbanas. No Egito, acerca de 3000 a $2000 \mathrm{AC}$, as rochas foram utilizadas in natura na construção das pirâmides, palácios, edificações e na pavimentação. Na China, no terceiro milênio antes de Cristo, as rochas areníticas eram usadas na confecção de vasos, murais e outros objetos de adorno, além de edificações, praças e para o ajardinamento. Na América Central, os maias utilizaram as rochas como objeto de adorno pessoal, onde eram trabalhadas com grande sofisticação.

No Brasil, durante a colonização, no período entre 1750 e 1890 , o Império utilizou as rochas brutas ou parcialmente trabalhadas para a construção de fortes, palácios, edificações urbanas e na pavimentação das cidades mais desenvolvidas. A arte sacra também aproveitou as reservas de esteatitos e serpentinitos da região de Minas Gerais como matéria prima para a construção de um enorme acervo de estátuas de santos e para reconstruir passagens religiosas e bíblicas para a ornamentação de igrejas, praças e passeios públicos.

Com a mudança do regime político, a República ostentou uma nova arquitetura, mais elaborada e artística, construindo museus, palácios de governo e outras obras públicas utilizando rochas encontradas no território nacional como arenitos e mármores e também importando materiais rochosos de outros países, princi- 
palmente, calcáreos da França e mármores da Itália.

No Rio Grande do Sul, as obras do período republicano que mais se destacam são a Catedral Metropolitana de Porto Alegre, o Museu Júlio de Castilhos e o Palácio do Governo do Estado do Rio Grande do Sul. A Catedral começou a ser construída no início do século XX a partir de granitos da região de Porto Alegre e a cúpula foi coberta por mármores provenientes do Espírito Santo.

A Catedral Metropolitana de Porto Alegre é uma importante obra da arquitetura sacra no estado do Rio Grande do Sul. Única no emprego de rochas ornamentais e no seu trabalho de cantaria, a Catedral foi projetada em estilo neo-renascentista pelo arquiteto romano João Batista Giovenalle. A concepção do projeto objetivou dar a cúpula notável grandiosidade, destacando-se como a segunda maior do mundo, com um diâmetro interno de aproximadamente 18 metros. A construção da Catedral estendeu-se desde 1921, com o início das obras da nave principal até a conclusão da cúpula em 1986. O longo período de execução da obra resultou em diversas modificações no projeto original. O corpo principal da igreja foi todo construído em blocos de granito, que foram extraídos da região da Vila Nova, situada nos arredores da área urbana de Porto Alegre. A cúpula, projetada para ter um revestimento de cobre, acabou sendo coberta por chapas de mármore dolomítico silicoso (Fig. 1). Apesar do pouco tempo de sua conclusão, são diversos os problemas gerados pela ausência de um projeto criterioso para adequação do novo material somado as limitações de uso do revestimento de mármore.

A geometria da Cúpula é o resultado da intersecção de doze cilindros com linhas adjacentes sobre um plano horizontal paralelo ao terreno e orientado

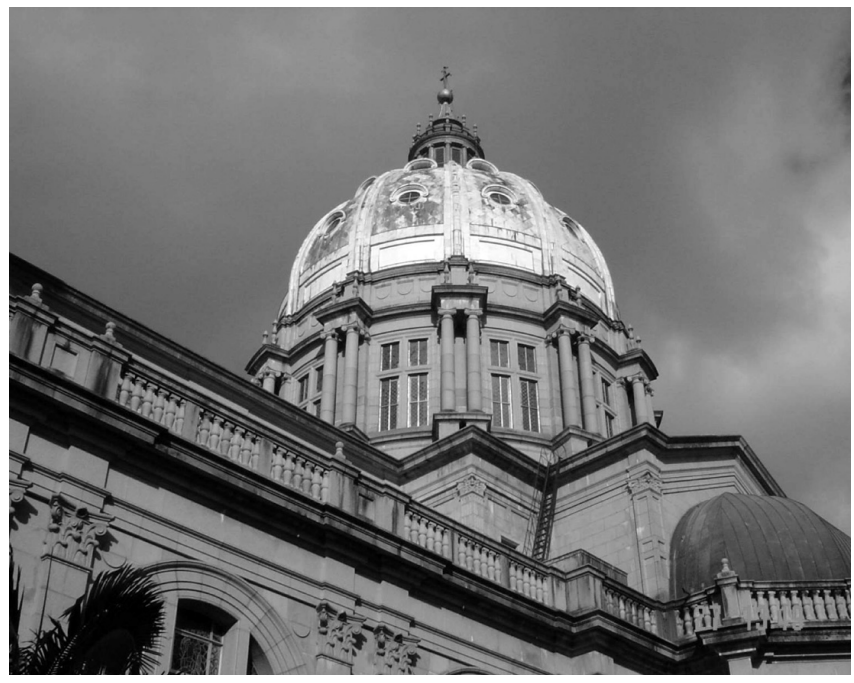

Figura 1 - Vista geral da Cúpula da Catedral Metropolitana de Porto Alegre destacando o enegrecimento parcial do revestimento de mármore.

segundo os pontos cardeais (Fig. 2). As costelas representam as linhas de intersecção entre as quais são confinadas as velas, que correspondem às porções do cilindro interseccionado (Fig. 3). A seção ortogonal de cada vela é representada por uma cônica, as quais são unidas por três vigas cintas localizadas na sua base, na parte intermediária e a última na região superior onde há a intersecção das nervuras quando nasce o lanternin. Internamente, a cúpula é constituída por duas cascas de concreto armado (aço CA-24) uma interna e outra externa, ambas com aproximadamente oito (08) centímetros de espessura, tendo um revestimento externo composto por uma parede de tijolos cimentados com cerca de 40

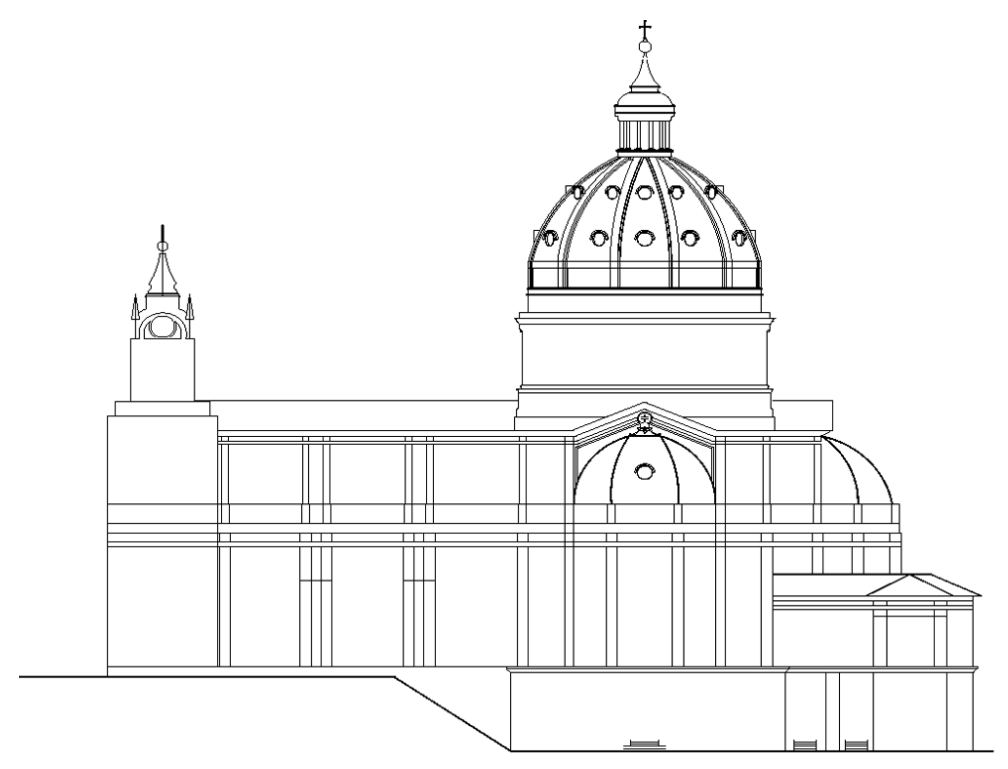

CROQUI - VISTA LATERAL

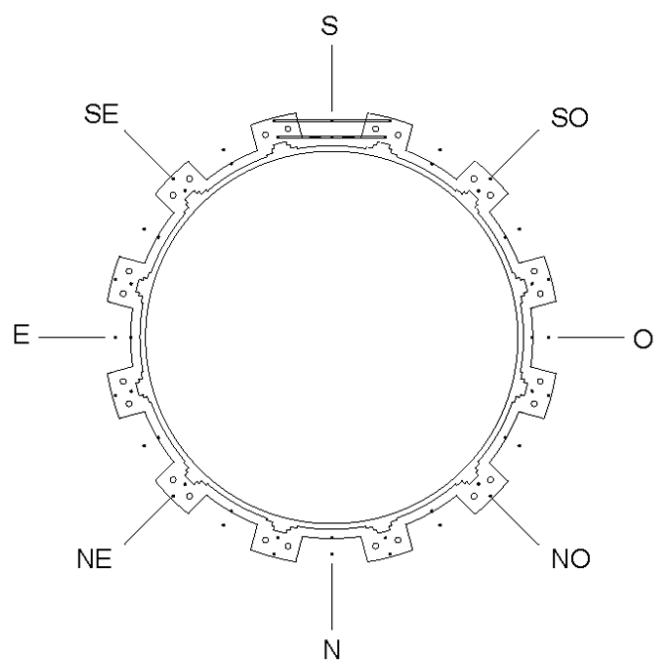

CROQUI - PLANTA

Figura 2 - Croqui lateral da Catedral Metropolitana de Porto Alegre e planta baixa da Cúpula. 


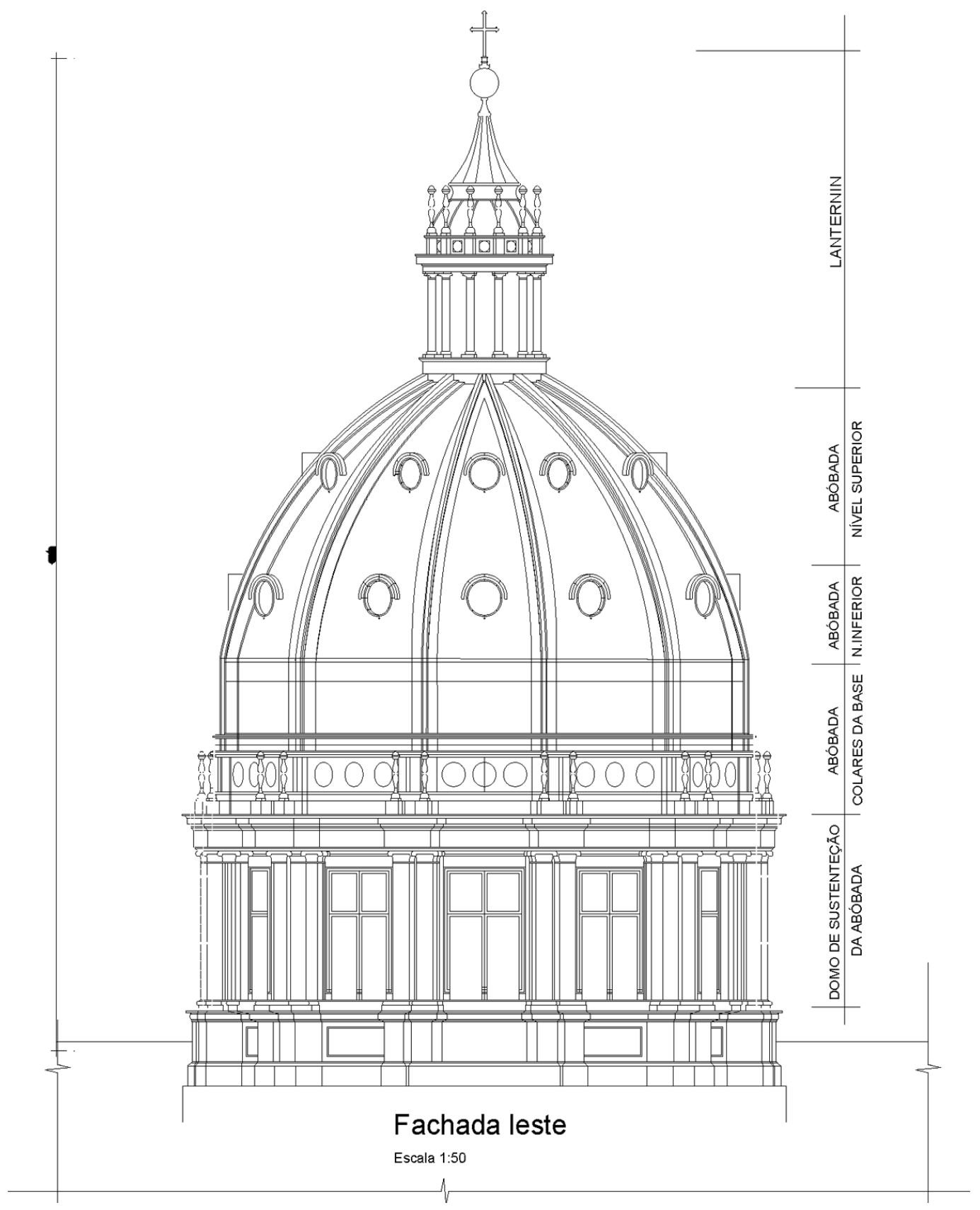

Figura 3 - Croqui detalhado da Cúpula e seus principais elementos constituintes.

$\mathrm{cm}$ de espessura. As placas de mármore foram assentadas sobre esta parede através de argamassa de cimento, cal e areia, auxiliadas por um sistema de fixação através de grampos metálicos galvanizados em tela de arame galvanizado fixada na estrutura da cúpula.

A ausência de elementos estruturais que permitissem a dilatação dos materiais e a colocação das placas com juntas secas foram os principais causadores de uma série de problemas estruturais que afetaram a cúpula e a parte interna da catedral. A geração de fissuras de dilatação e o desplacamento das chapas proporcionaram a ocorrência de infiltrações, que resultaram em processos de corrosão, dissolução e reprecipitação de cimento carbonático hidratado. As principais patologias diagnosticadas sobre a Cúpula da Catedral Metropolitana de Porto Alegre foram alteração cromática, concreção, destacamento, eflorescência, erosão, fraturamento, fissuração, incrustação, lacuna, mancha, pátina biológica, pitting e presença de vegetação.

Os principais danos encontrados na avaliação da cúpula são resultado da atuação do intemperismo químico, físico e biológico que se manifesta através de um conjunto de patologias onde se destaca o enegrecimento superficial por ação de microorganismos, fissuras de dilatação, infiltrações, desacoplamento das chapas de mármore, desgaste de material e dissoluções.

A análise desenvolvida neste estudo teve como base à identificação in situ e o mapeamento das diversas patologias, acompanhados por estudos petrográficos e de microscopia eletrônica de varredura. O principal objetivo deste trabalho é o diagnóstico dos problemas estruturais e materiais encontrados na cúpula da Catedral 
Metropolitana de Porto Alegre.

No Brasil, em face de sua ampla diversidade de edificações, são ainda muito poucas as medidas de conservação e preservação deste patrimônio histórico. Em países europeus como a França, Inglaterra, Alemanha e Itália a geologia está agregando informações importantes sobre o comportamento dos materiais rochosos frente as exigências de conservação nas atuais condições climáticas e particularidades locais de cada região (Dolcini, 1981; Lazzarini \& Tabasso, 1986; Accardo \& Vigliano, 1989; Fitzner et al. 1995). Este trabalho procura introduzir a contribuição geológica em uma nova área de atuação das geociências no país.

\section{PETROGRAFIA E MINERALOGIA DOS} MÁRMORESUTILIZADOSNOREVESTIMENTO DA CÚPULA As placas que revestem a cúpula são de Mármore Branco Pinta Verde proveniente do estado do Espírito Santo, possuindo dimensões de $50 \mathrm{~cm} \times 50$ $\mathrm{cm}, 36 \mathrm{~cm} \times 50 \mathrm{~cm}, 45 \mathrm{~cm} \times 50 \mathrm{~cm}, 35 \mathrm{~cm} \times 50 \mathrm{~cm}, 80 \mathrm{~cm} \times 50-$ $\mathrm{cm}, 12 \mathrm{~cm} \times 50 \mathrm{~cm}, 12 \times 50 \mathrm{~cm}$, e espessuras entre $2 \mathrm{~cm}$ e $2,5 \mathrm{~cm}$. Apresentam cor branca a cinza claro, localmente com níveis milimétricos a centimétricos de cor verde clara a cinza esverdeado. Petrograficamente correspondem a mármores dolomíticos, classificados como tremolita, diopsídio e olivina mármores. Possuem textura dominante granoblástica grossa, com tamanho entre $2 \mathrm{e}$ $6 \mathrm{~mm}$, podendo atingir entre 2 e $4 \mathrm{~cm}$ (Fig. 4).

A maioria das chapas apresenta estrutura maciça. De modo subordinado, apresentam estrutura bandada, com níveis contínuos e irregulares de espessura milimétrica ( 2 a $10 \mathrm{~mm}$ ) ou até centimétrica ( 3 a 10 $\mathrm{cm}$ ), compostos por proporções variadas de silicatos de $\mathrm{Ca}$ e Mg. Em algumas chapas ocorrem fissuras preenchidas por veios de carbonato com espessuras entre 5 a 15 centímetros e limites retos a pouco curvilíneos.

A composição mineral dos mármores é dominada por carbonatos, com presença subordinada de Tremolita, Diopsídio e Olivina (Figs. 5a, 5b e 5c). Para a determinação do tipo de carbonato foi realizado teste químico a partir da reação da rocha com uma solução de Vermelho de Alizarina $\left(\mathrm{C}_{14} \mathrm{H}_{7} \mathrm{NaO}_{7} \mathrm{~S} . \mathrm{H}_{2} \mathrm{O}\right)$, que reage com a calcita tingindo o mineral com cor rosada. Foi constatado a presença de dois tipos de carbonatos, Calcita $\left(\mathrm{CaCO}_{3}\right)$ e Dolomita $\left(\mathrm{CaMgCO}_{3}\right)$, em quantidades variáveis e gerais entre 40 a 70\% (Fig. 5d).

Ambos minerais se caracterizam por apresentar baixa estabilidade em condições intempéricas, principalmente em presença de água. A molécula de $\mathrm{CO}_{3}^{-2}$ dos carbonatos é muito instável em presença do íon hidrogênio $\left(\mathrm{H}^{+}\right)$. A calcita a temperatura ambiente é pouco solúvel na água pura $(0,02 \mathrm{~g} / 1)$, mas quando em contato com anidrida carbônica dissolvida em água torna-se muito solúvel $(1 \mathrm{~g} / 1)$. Também a dolomita, embora em menor quantidade que a calcita, é solúvel em água carbônica $(0,03 \mathrm{~g} / 1)$ (Lazzarini \& Tabasso, 1986).

A disponibilidade de água causou a dissolução da superfície da chapa de mármore, resultando na perda do brilho de polimento e na formação de uma superfície rugosa e áspera, em conseqüência da maior dissolução

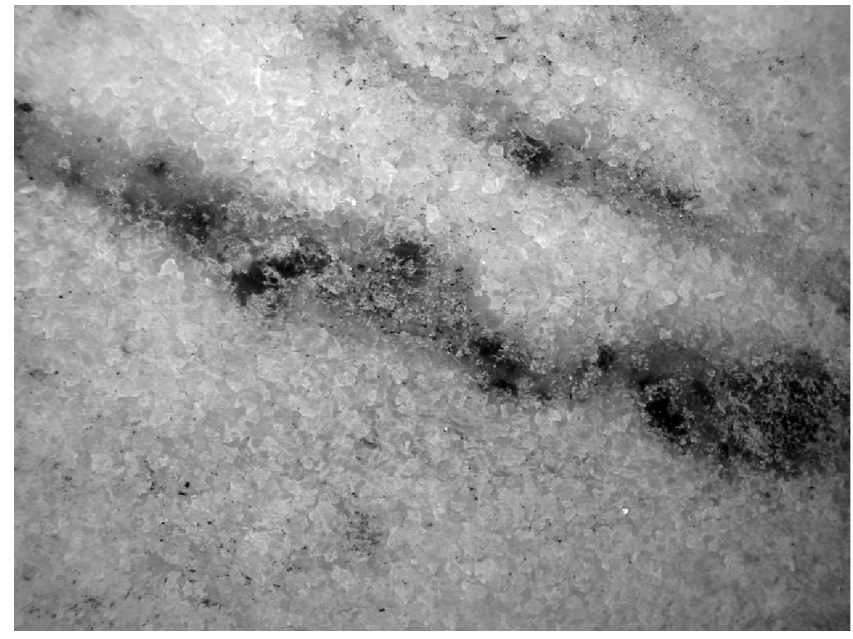

Figura 4-Chapa de mármore com textura granoblástica grossa.

da calcita em relação à dolomita (Fig.6). Próximo às zonas fraturadas e ao redor dos grampos metálicos de fixação de algumas chapas, a absorção e percolação da água em microdescontinuidades foram responsáveis pela dissolução dos carbonatos e pela desagregação da rocha.

\section{PRINCIPAIS PATOLOGIAS DIAGNOSTICA-} DAS E SEUS EFEITOS As obras arquitetônicas e os monumentos são afetados por ação do intemperismo ocorrendo um desgaste natural dos materiais que as constituem como rochas, materiais ligantes (cimento, argamassa, e até mesmo, o concreto). A Catedral Metropolitana de Porto Alegre está situada em uma área central da cidade, estando sujeita aos efeitos climáticos regionais, acentuado pelos efeitos locais resultantes das edificações a sua volta e dos poluentes atmosféricos, resultando em taxas variáveis de insolação e temperaturas, circulação de ar, umidade, chuvas ácidas, entre outros. A atuação dos processos intempéricos resulta na deterioração das construções e monumentos arquitetônicos. As modificações nas rochas e outros materiais utilizados caracterizam, sob a ótica da conservação, o grau de degradação da obra. A caracterização do estado de conservação de uma obra arquitetônica é realizada através da fotodocumentação, do mapeamento litológico e do mapeamento detalhado das formas de intemperismo (Silva \& Roeser, 2003).

No diagnóstico sobre a análise do estado de conservação da Cúpula da Catedral Metropolitana as principais formas de intemperismo observadas foram a perda de material rochoso, descoloração e depósito, desintegração e fissuras (Fitzner et al. 1995). Estas formas são responsáveis pelos principais problemas identificados na conservação da Cúpula da Catedral Metropolitana.

Modificação da cor original do mármore As modificações na cor das chapas de mármore são causadas pela presença superficial de plantas aéreas e microorganismos, pela precipitação de hidróxidos de ferro e/ ou de cimento carbonático hidratado. As plantas aé- 

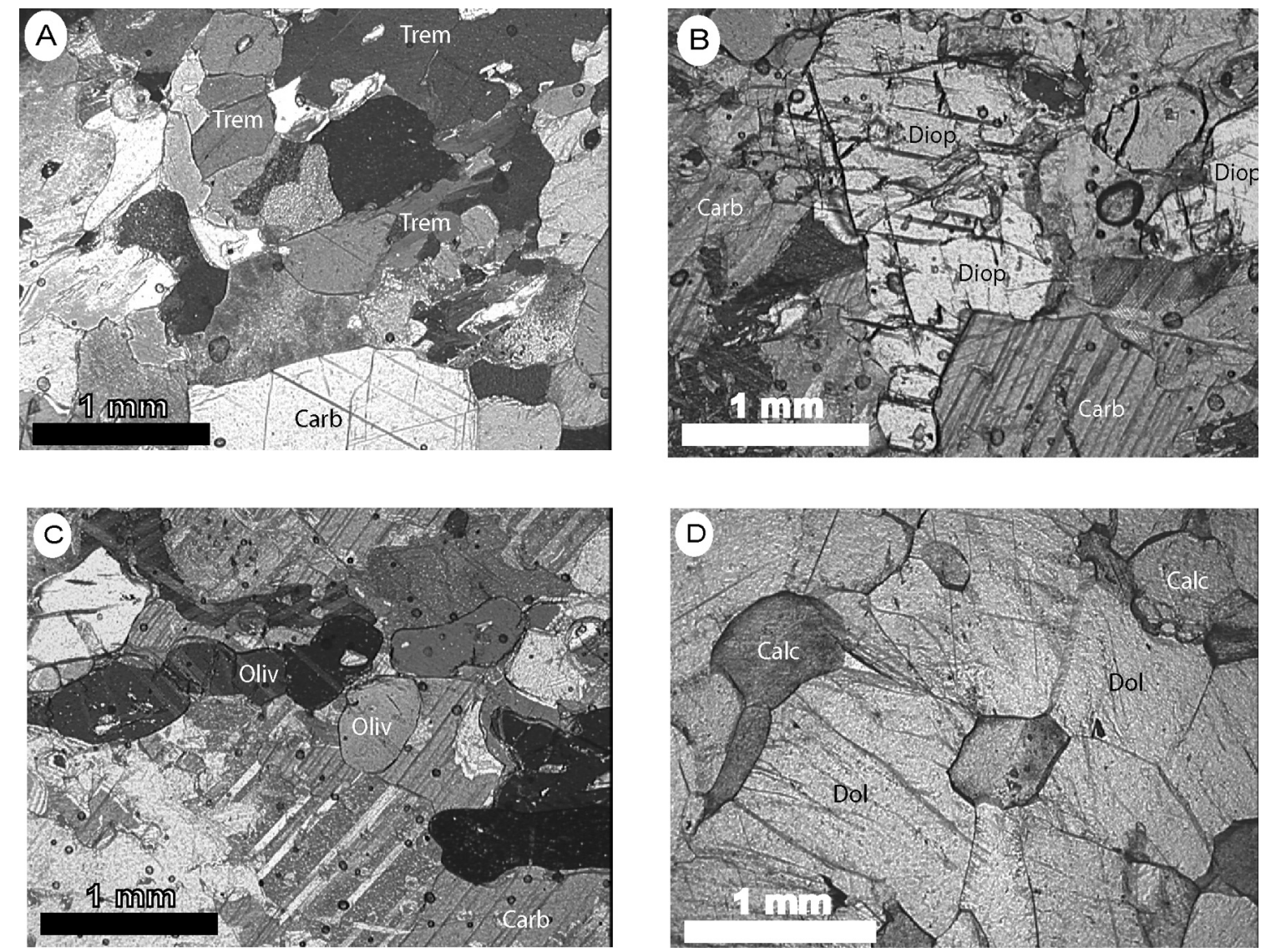

Figura 5 - Fotomicrografias com as principais caraterísticas composicionais e texturais dos mármores que revestem a Cúpula da Catedral Metropolitana de Porto Alegre. a) Tremolita mármores, b) Diopsídio mármores, c) Olivina mármores e d) textura granoblástica poligonal grossa caracterizada pela dolomita, com destaque para os cristais mais escuros de calcita pigmentados pelo corante Vermelho de Alizarina.

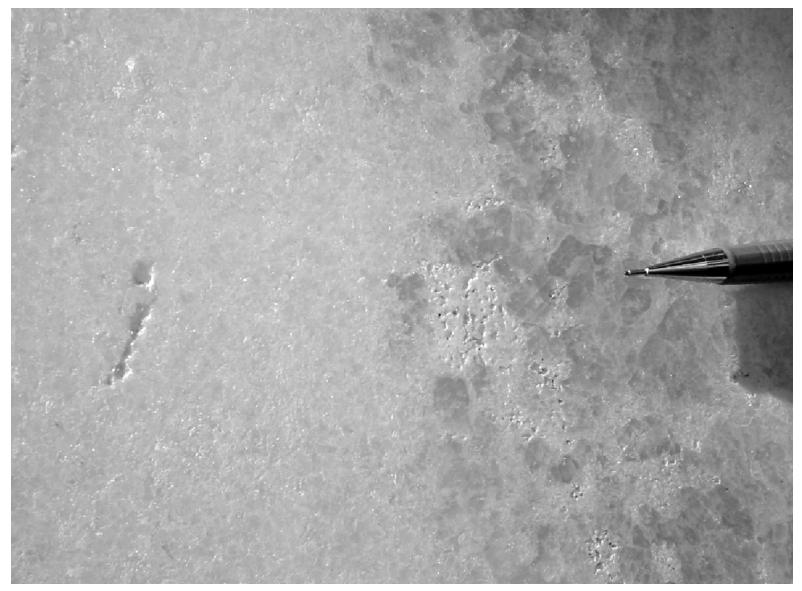

Figura 6 - Intensa dissolução de banda rica em calcita.

reas e os microorganismos possuem cor verde e com sua morte adquirem cor preta, sendo um dos principais agentes modificadores da cor original da cúpula (Fig. 7). A proliferação destes organismos ocorre em toda a

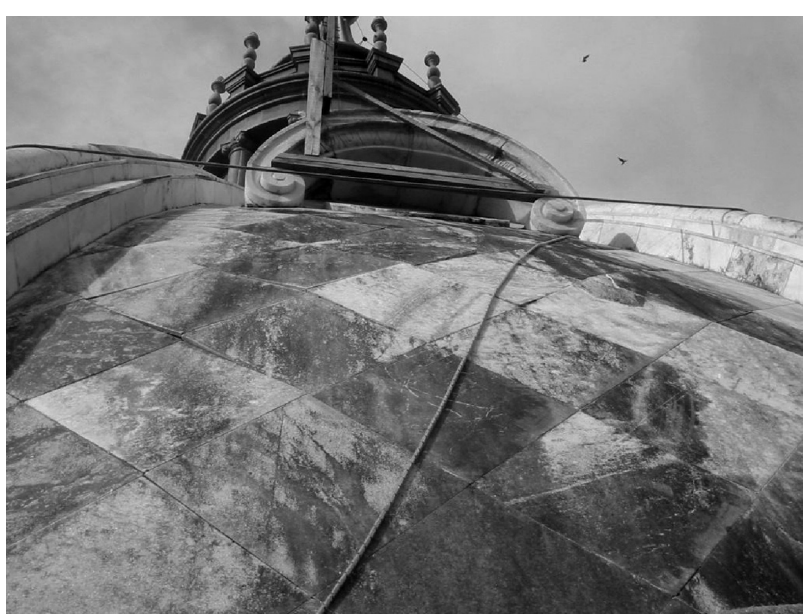

Figura 7 - Vista em detalhe do enegrecimento parcial do revestimento de mármore da Cúpula da Catedral Metropolitana de Porto Alegre.

cúpula, porém em intensidades diferentes, com concentração principal nas porções sul e norte da mesma, quando chegam a cobrir cerca de 50 a $65 \%$ da área de exposição. 
Na porção superior da cúpula, no seu segmento sul, ocorre uma mancha de cerca de 40 centímetros por 60 centímetros de hidróxido de ferro de cor castanha escura a laranja. Esta mancha está relacionada à corrosão do cabo de aço que sustenta a luz de sinalização situada no topo do telhado do lanternim. Próximo à extremidade onde está fixado, o cabo de aço sofre com a dissolução por água da chuva e umidade e o produto desta oxidação é a formação de hidróxidos de ferro, que se precipita nas chapas de mármore dando origem à mancha. A reação com a água da chuva faz com que os hidróxidos de ferro escorram a partir da mancha, criando um rastro de coloração alaranjada com largura entre $40 \mathrm{~cm}$ a 2 metros.

Em diversos locais da cúpula observa-se no mármore uma tênue passagem da cor branca para um amarelo muito claro. Este tom manifesta-se de modo disperso e homogêneo, muito localizadamente, como manchas de tom alaranjado. Esta pigmentação tem origem no retrabalhamento (nova dissolução) da mancha de hidróxido de ferro e dispersão desta solução com baixa concentração via água da chuva e vento. Poderiam ser acrescidos ainda como contribuintes locais deste tom amarelo à corrosão dos grampos de fixação de algumas placas que foram desacopladas e a oxidação da barra galvanizada principal da cerca metálica que rodeia a base do lanternim.

Outro tipo comum de mancha é gerado pela precipitação (incrustação) de cimento carbonático hidratado sobre a superfície da chapa de mármore e ao longo de descontinuidades como os limites das chapas e fissuras de dilatação (Fig. 8a). Estas manchas mostram cor cinza clara a esbranquiçada, localmente marrom claro, formas alongadas com disposição subvertical e larguras da ordem de 20 a 50 centímetros. As incrustações são constituídas por diversas camadas muito finas $(<0,1 \mathrm{~mm})$ de cimento carbonático hidratado e apresentam espessuras individuais entre 0,2 a $1,5 \mathrm{~mm}$, podendo atingir até $1 \mathrm{~cm}$ de espessura total (Fig. 8b). Em porções localizadas chegam a formar cristais de calcita com formas subidiomórficas de tamanhos entre 0,1 a $0,5 \mathrm{~mm}$. As incrustações são observadas na porção inferior da cúpula, próximo à junção das colunas (costelas) com a parede das velas da cúpula. Em vários locais, as incrustrações transicionam para estruturas do tipo estalactites e estalagmites, que representam precipitados alongados de calcita depositados em zonas de intensa circulação e acumulação de águas ricas em $\mathrm{Ca}\left(\mathrm{HCO}_{3}\right)_{2}$. As estalactites possuem formas alongadas com comprimentos entre 1 e $7 \mathrm{~cm}$, pendentes do limite das paredes próximas ao parapeito localizado no anel externo da base da cúpula. Nesta mesma porção do anel da base da cúpula, porém na sua porção inferior, a acumulação de cimento carbonático produz estalagmites, que são precipitados de calcita alongados com crescimento de baixo para cima. Comumente estas estruturas apresentam altura entre 2 a 10 centímetros e larguras entre 5 a 20 centímetros. Apresentam espessuras entre 1 a $25 \mathrm{~mm}$ e possuem estrutura interna acamadada constituída por diversas lâminas muito finas de cimento carbonático hi-
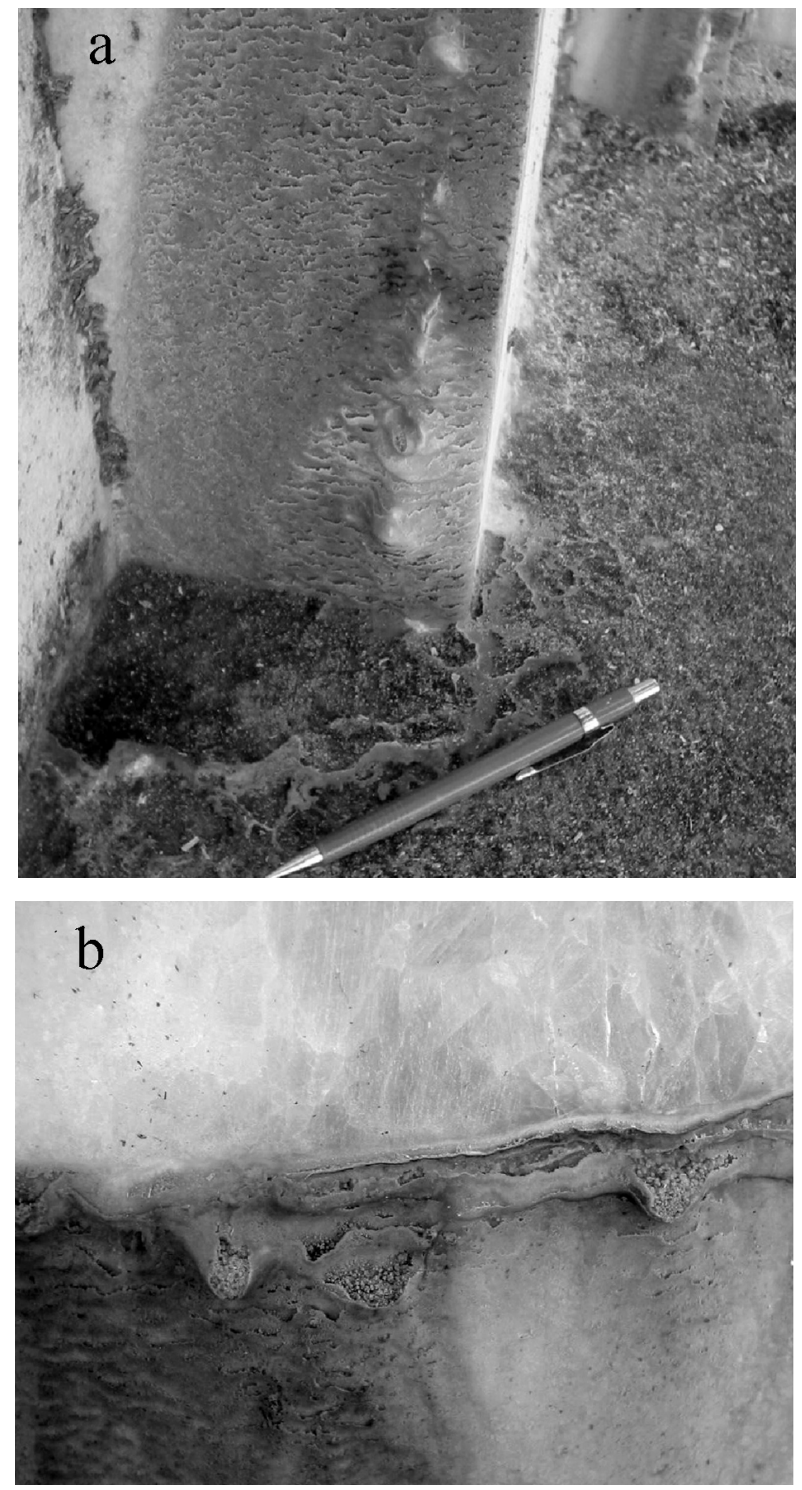

Figura 8 - Precipitação de cimento carbonático hidratado no contato entre a chapa de mármore e o granito situado no anel inferior do domo de sustentação da Cúpula (a) e Detalhe do acamadamento interno do cimento carbonático hidratado precipitado (b).

dratado. A origem destas incrustações está relacionada principalmente a dissolução da mistura de argamassa, cimento, cal e areia que assenta as placas de mármore.

Fissuras de Dilatação As chapas de mármore quase não apresentam registro de fraturas tectônicas. Estas fraturas quando presentes estão preenchidas por veios de carbonatos de espessuras centimétricas e encontram-se seladas. Entretanto, próximo à junção entre as colunas (costelas) que sustentam a cúpula e as paredes das velas ocorrem inúmeras fissuras de dilatação. As fissuras são descontínuas, com formas curvilíneas e irregulares, de limites serrilhados e superfície rugosa. Podem ser reconhecidos três grupos distintos de fissuras de dilatação 
caracterizadas por sua extensão, disposição e localização na edificação.

As fissuras mais comuns estão situadas nas proximidades da junção entre as colunas (costelas) e a parede das velas da cúpula, com disposição aproximadamente perpendicular às colunas, com início das fissuras a partir do limite da mesma em direção oposta (Fig. 9a). Apresentam formas retilíneas, com limites interlobados, superfície rugosa e extensões entre 20 e 50 centímetros, podendo atingir até 1,5 metros. Cortam entre 2 e 3 chapas de mármore, ocorrendo comumente em grupos de 2 a 5 fissuras subparalelas com espaçamento entre 5 a 15 centímetros. Freqüentemente, estão preenchidas por um cimento carbonático hidratado precipitado a partir da dissolução do cimento contido na argamassa utilizada para fixação das chapas. Em geral o preenchimento mostra espessuras entre 1 a 2 milímetros.

Um segundo grupo de fissuras está localizado na porção inferior do anel externo situado na base da cúpula. As fissuras começam a partir dos anéis da base do domo de sustentação da Cúpula e se irradiam de modo perpendicular ao alongamento do anel por extensões que variam entre $40 \mathrm{~cm}$ até 2 metros ou mais. Mostram formas aproximadamente curvilíneas, com limites interlobados e superfície rugosa, ocorrendo isoladas ou em grupos de 2 a 3 fissuras subparalelas com espaçamento entre 5 a 15 centímetros (Fig. 9b). Cortam entre 3 a 5 chapas de mármore e estão preenchidas por cimento carbonático hidratado, apresentando espessuras entre 0,5 a 1,5 milímetros.

O grupo de fissuras de dilatação mais subordinado pode ser observado nas porções intermediárias e superiores da cúpula. São estruturas com disposição radial caracterizada por grupos de 3 a 6 fissuras com formas retilíneas a pouco curvilíneas, extensões entre 15 a $35 \mathrm{~cm}$ e espaçamento entre 3 a 10 centímetros.

A localização, forma e tipo das fissuras são indicativas de sua origem recente e estão associadas a diferenças do coeficiente de dilatação térmica entre os três principais materiais que constituem a cúpula: concreto armado, parede de tijolos com cobertura de argamassa e chapas de mármore. Os valores do coeficiente de dilatação térmica linear para os mármores dolomíticos que cobrem a cúpula são de 0,00089 milímetro/metro, inferiores a $0,00012 \mathrm{~mm} / \mathrm{m}$, valor máximo permitido pelas normas da ASTM-E228 e da ABNT-NBR 12756. A análise deste dado reforça a hipótese que não é a dilatação da rocha a responsável pelas fissuras encontradas nas chapas.

Um dos principais problemas da cúpula está relacionado ao efeito da dilatação térmica dos materiais que a constituem e as chapas de mármore do revestimento externo. Como as chapas foram colocadas por um tipo de assentamento denominado junta seca, ou seja, sem a existência de um espaço mínimo entre as chapas, a dilatação dos materiais sobre as quais estão assentadas origina esforços internos que forçam as placas umas contra as outras, ocasionando o desalinhamento e o desplacamento parcial (Fig.10). A penetração de água da chuva através das fendas geradas pelo de-
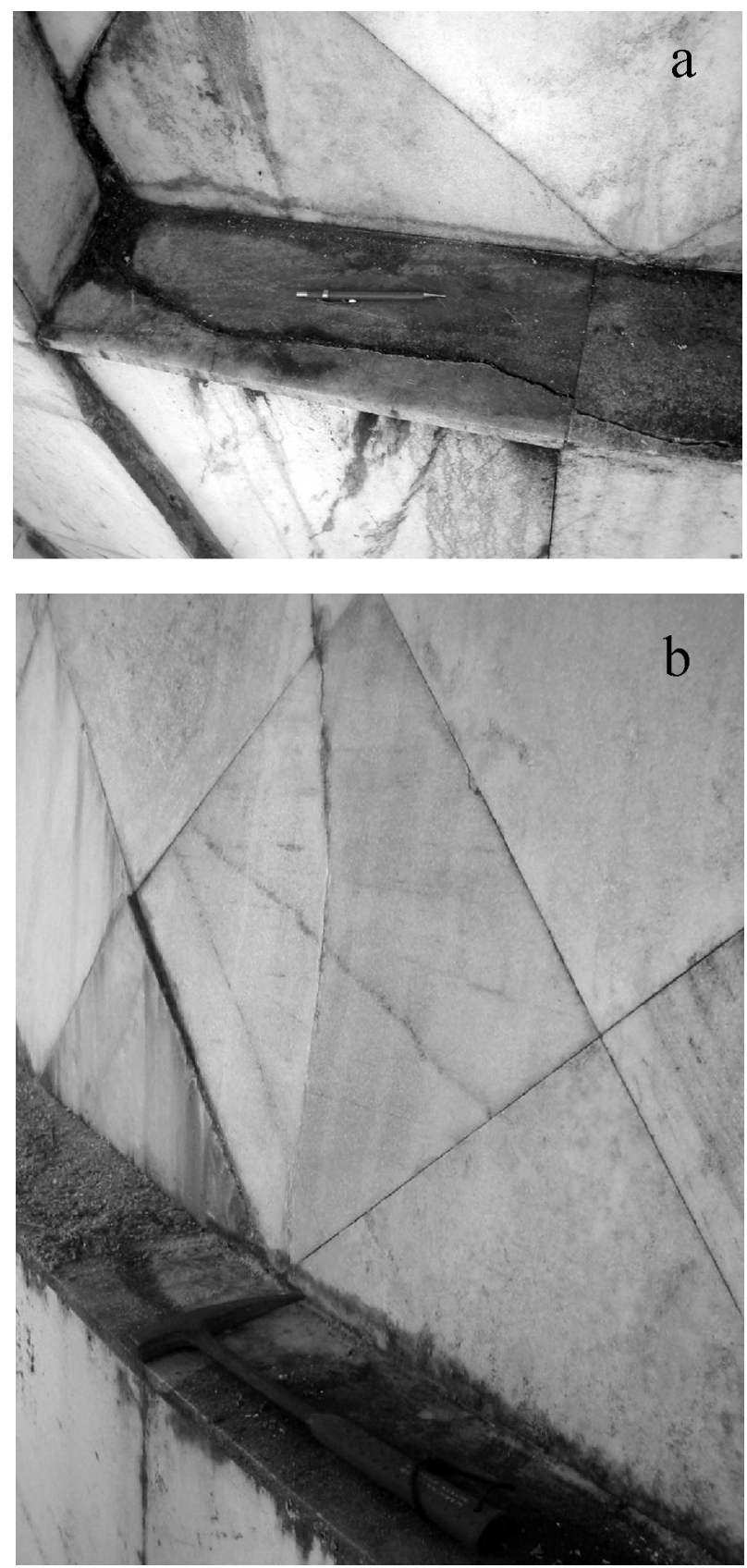

Figura 9 - Junta de dilatação associada com a expansão da junção entre a coluna (costela) situada a esquerda e o parapeito dos colares da base da Cúpula, parcialmente preenchida por cimento carbonático hidratado (a) e Junta de dilatação de forma curvilínea situada entre o parapeito dos colares da base da Cúpula e a parede (vela) cortando duas chapas de mármore do revestimento (b).

sacoplamento ocasiona a dissolução do cimento do revestimento externo da parede de material (tijolo), diminuindo a adesão da chapa na parede. A reação da água da chuva $\left(\mathrm{H}_{2} \mathrm{O}+\mathrm{H}_{2} \mathrm{CO}_{3}, \mathrm{HNO}_{3}, \mathrm{H}_{2} \mathrm{SO}_{4}\right)$ com o cimento (que é composto por uma mistura de calcáreo, argilas e óxidos de ferro e magnésio), ocasiona a dissolução do mesmo e a solubilização dos materiais que o compõe com a água. Este material é transportado pela superfície 
das chapas de mármore da cúpula, através de fendas entre as chapas, e nos espaços internos gerados atrás das chapas pelo deslocamento e desacoplamento das mesmas pela dilatação. A precipitação deste material ocasiona na porção superior e intermediária da cúpula o preenchimento de fendas por um cimento carbonático hidratado composto por silicatos e aluminatos de Ca hidratados. Na porção inferior da cúpula ocorre preenchimento de fissuras de dilatação e de fendas entre chapas, zonas com incrustrações de carbonatos sobre as chapas com disposição alongada na subvertical e formação de estalactites e estalagmites no anel inferior da cúpula.

Para a análise e diagnóstico dos principais problemas encontrados na cúpula da Catedral Metropolitana foi realizado o mapeamento das principais patologias, que se encontram representados na figura 11. A figura 12 mostra uma das velas em detalhe, ressaltando a presença de outras patologias encontradas.

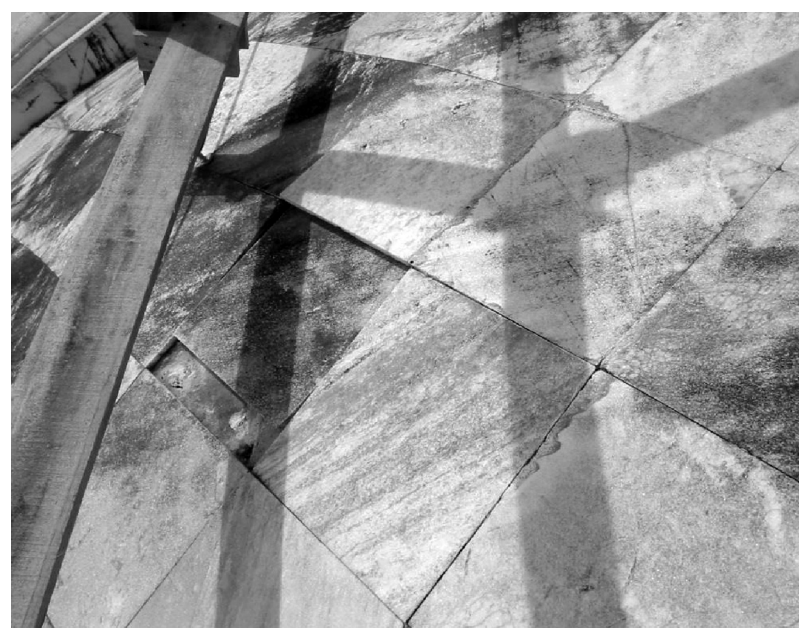

Figura 10 - Detalhe do desacoplamento das placas de revestimento na parte superior da Cúpula.

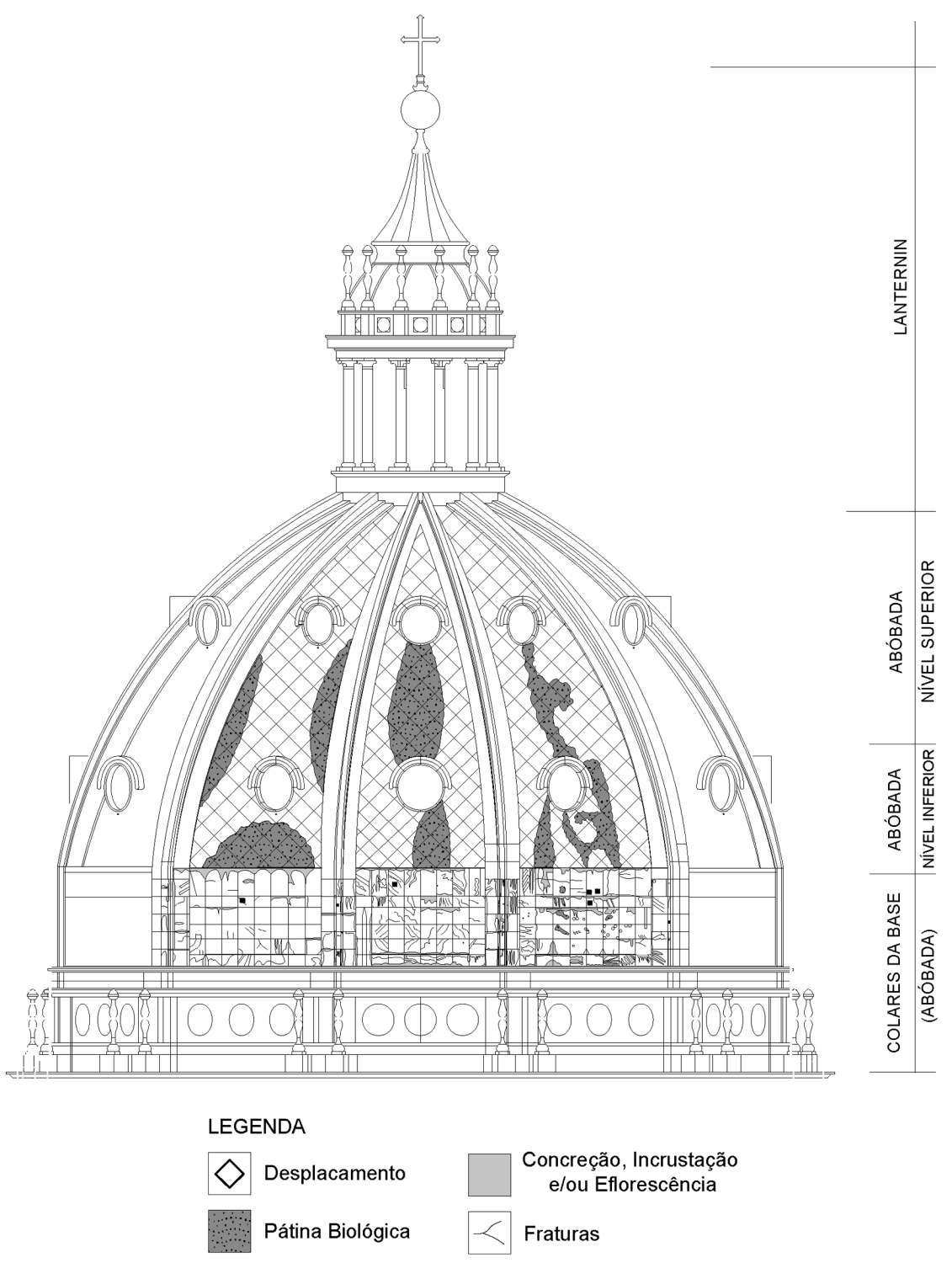

Figura 11 - Mapa da fachada Leste da Cúpula da Catedral Metropolitana de Porto Alegre com indicação das principais patologias identificadas. 


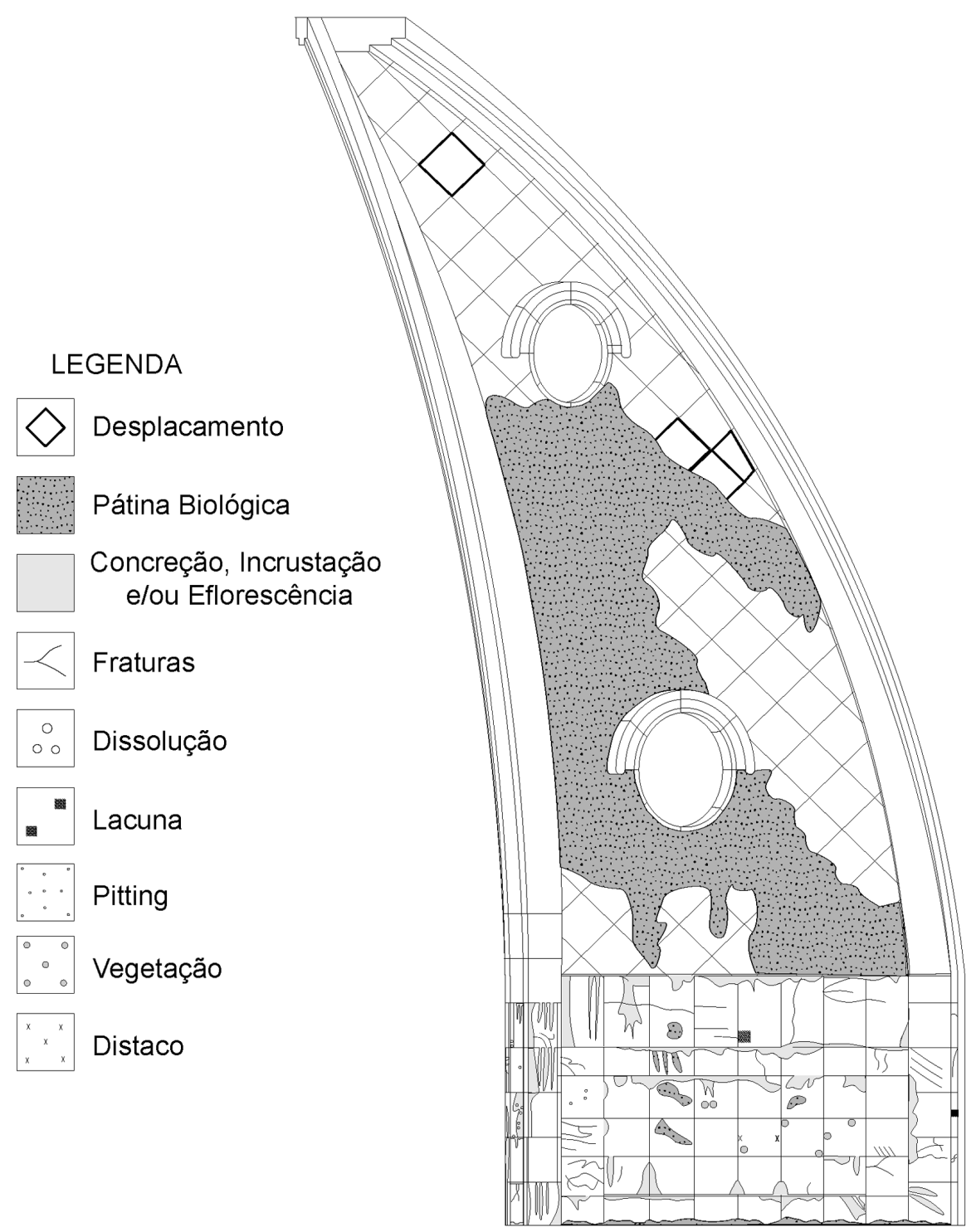

Figura 12 - Detalhe de uma das velas da Cúpula com a identificação das principais patologias identificadas.

ENSAIOS TECNOLÓGICOS Os ensaios tecnológicos dos mármores mostraram resultados plenamente satisfatórios, com um valor de densidade aparente seca de $2,8 \mathrm{Kg} / \mathrm{m}^{3}$, superior ao mínimo de $2,7 \mathrm{Kg} / \mathrm{cm}^{3}$ exigido pelas normas nacionais (NBR 12766) e internacionais. O valor para absorção d'água de 0,06 é muito inferior ao máximo de $1 \%$, enquanto que o valor de 0,17 para porosidade é também inferior ao máximo de 0,4 da mesma norma anterior. O desgaste abrasivo (AMSLER) é elevado, com um valor de 6,92 mm, muito superior ao máximo de $1 \mathrm{~mm}$, recomendado pela norma ABNT (NBR 12042). Este desgaste elevado indica que esta rocha não deve ser utilizada como revestimento externo, principalmente como piso externo e/ou interno. O valor para compressão uniaxial no estado natural é de 86,4 MPa e de 86,7 MPa no estado de gelo/degelo, superior ao mínimo de $80 \mathrm{MPa}$ indicado pela norma ABNT (NBR 12767). Da mesma forma, a resistência ao impacto duro é de $35 \mathrm{~cm}$, um pouco inferior ao mí- nimo de $40 \mathrm{~cm}$ sugerido pelas normas nacionais.

CONSIDERAÇÕES FINAIS Os problemas diagnosticados na cúpula da Catedral Metropolitana de Porto Alegre resultaram da concepção e execução da obra, associados à utilização de material inadequado. Após análises das variantes responsáveis pelo estado de conservação dos revestimentos da cúpula conclui-se que o material especificado não possui características tecnológicas adequadas ao uso ao qual foi submetido.

A deterioração encontrada no revestimento da Cúpula resultou da interação entre a rocha e os agentes intempéricos, resultando na dissolução da superfície das chapas e dos minerais mais solúveis como a calcita e a dolomita. Minerais como a calcita e a dolomita são facilmente solubilizados pelas águas de caráter ácido levando a sua decomposição química e auxiliando na desagregação física da rocha. No entanto, apesar das características tecnológicas do mármore não favorece- 
rem a sua colocação nestas condições, sua vida útil seria maior caso houvesse tido um projeto que respeitasse suas características e suas solicitações.

A variação térmica é um dos mecanismos de degradação que mais influenciaram no atual estado de conservação dos revestimentos em mármore da Cúpula da Catedral. A inexistência de um sistema de refrigeração e ventilação adequado no espaço existente entre as duas cascas que constituem a abóbada, resulta na falta de troca térmica entre o meio externo e o interno (estrutura/revestimento). A ausência de estruturas que absorvam a dilatação dos diversos materiais que compõem a cúpula, associado ao assentamento das chapas de mármore com junta seca, resultou no desenvolvimento de fissuras de dilatação e no desplacamento parcial das chapas de mármore.

A baixa dureza e a dissolução dos carbonatos facilitaram a fixação e o desenvolvimento de colônias de plantas aéreas e micro-organismos que acabaram por modificar a cor branca original por um revestimento enegrecido. $\mathrm{O}$ elevado desgaste do mármore, indicado pela perda do brilho e pela formação de uma superfície rugosa, reforçam a idéia de escolha inadequada para o revestimento da cúpula e atestam a acidez elevada da composição das águas meteóricas da região central da cidade de Porto Alegre. A falta de manutenção atribuída às dificuldades de acesso e a ausência de uma estrutura para a realização de reparos também são indicativas de inadequação do projeto original.

A reunião dos dados e as observações discutidas acima reafirmam a importância da análise geológica dos materiais durante as fases de elaboração, execução e manutenção de obras públicas como monumentos, construções e passeios públicos. Neste sentido, pode ser importante introduzir com base nos objetivos do projeto, a necessidade de análise dos ensaios tecnológicos dos materiais rochosos a serem utilizados.

Agradecimentos A Cúria Metropolitana de Porto Alegre pelo acesso a área de estudo e de documentos históricos. Ao Conselho Nacional de Pesquisa (CNPq), processo $n^{\circ} 301915 / 2006-7$, de Ruy Paulo Philipp, pela concessão de bolsa de produtividade em pesquisa. Ao professor Dr. Luis Fernando De Ros pelo acesso e uso do microscópio petrográfico e pelas fotomicrografias. Aos revisores do corpo consultivo da RBG pelas sugestões e críticas ao texto original.

\section{Referências}

Accardo G. \& Vigliano G. 1989. Materiali Lapidei, in "Strumenti e Materiali del Restauro: Metodo di analisi , misura e controllo. Edizioni Kappa, Roma, 111p.

Associação Brasileira de Normas Técnicas. 1992a. NBR 12042 - Materiais inorgânicos. Determinação do desgaste por abrasão. $3 \mathrm{p}$.

Associação Brasileira de Normas Técnicas. 1992b. NBR 12763 - Rochas para revestimento. Determinação da resistência a flexão. 3p.

Associação Brasileira de Normas Técnicas. 1992c. NBR 12764 - Rochas para revestimento. Determinação da resistência ao impacto do corpo duro. $2 \mathrm{p}$.

Associação Brasileira de Normas Técnicas. 1992d. NBR 12765 - Rochas para revestimento. Determinação do coeficiente de dilatação térmica linear. $3 \mathrm{p}$.

Associação Brasileira de Normas Técnicas. 1992e. NBR 12766 - Rochas para revestimento. Determinação da massa especifica aparente, porosidade aparente e absorção d'água aparente. $2 \mathrm{p}$.

Associação Brasileira de Normas Técnicas. 1992f. NBR 12767 - Rochas para revestiment. Determinação da resistência à compressão uniaxial. $2 \mathrm{p}$.

Associação Brasileira de Normas Técnicas. 1992g. NBR 12767 - Rochas para revestimento. Análise petrográfica. $2 \mathrm{p}$.

American Society for Testing and Materials. 1992. ASTM - C 615. Standard specification for granite dimension stone.

Balém J.M. 1941. A Primeira Paróquia de Porto Alegre Nossa Senhora Madre de Deus. Centro da Boa Imprensa, Porto Alegre, 3p.
Di Benedetti V. 2006. Aplicação da análise petrográfica e de outras técnicas na investigação de patologias em rochas ornamentais e de revestimento. Dissertação de mestrado, Curso de Pós-Graduação em Geociências, Universidade Federal do Rio Grande do Sul (no prelo).

Dolcini L. 1981. Elementi de Biologia per il Restauro de Opere d'arte. Dalle lezioni Del Dott. Piero Tiano al corso de restuaro dell' Opficio delle Pietre Dure, Firenze, $67 \mathrm{p}$.

Fitzner B., Heinrichs K., Kownatzki R. 1995. Weathering forms: classification and mapping. Berlin, Verlag Ernst \& John, 88p.

Frazão E.B. 2002. Tecnologia de rochas na construção civil. São Paulo, Associação Brasileira de Geologia de Engenharia, 132p.

Lazzarini L. \& Tabasso M.L. 1986. Il Restauro della Pietra. Padova, CEDAM, 315p.

Silva M.E. \& Roeser H.M.P. 2003. Mapeamento e deteriorações em monumentos históricos de pedra-sabão em Ouro Preto. Revista Brasileira de Geociencias, 33(4):331338.

Souza A.C. 1994. Conservação Preventiva. Revista da Biblioteca Mario de Andrade, Imagens Literárias de São Paulo e Prevenção de Bens Culturais, 52:87-93.

Teixeira W., Toledo M.C.M., Fairchild T.R., Taioli F. 2000. Decifrando a Terra. São Paulo, Oficina de Textos-USP, 558p.

Manuscrito AE 025-2006

Submetido em 26 de junho de 2006 Aceito em 01 de dezembro de 2007 